\title{
Impact of Health Professionals on Health Promotion Activities in Japanese Worksites
}

\author{
Tomohiro Hirao ${ }^{1}$, Fumihiko Jitsunari ${ }^{1}$, Fumiyuki Asakawa ${ }^{2}$, Shigeru Suna ${ }^{1}$, \\ Takako Kitamado', Ichiro Fukunaga ${ }^{1}$, Noriaki Takeda ${ }^{3}$ and Hiroshi Kageyama ${ }^{4}$ \\ 'Department of Hygiene \& Public Health, Faculty of Medicine, Kagawa Medical University, \\ ${ }^{2}$ Colledge of Liberal Arts and Science, Kurashiki University of Science and the Arts, \\ ${ }^{3}$ Department of Medical Systems Management, Faculty of Medicine, Kagawa Medical University and \\ ${ }^{4}$ Kagawa Occupational Health Promotion Center
}

\begin{abstract}
Impact of Health Professionals on Health Promotion Activities in Japanese Worksites: Tomohiro Hirao, et al. Department of Hygiene \& Public Health, Faculty of Medicine, Kagawa Medical University-We tried to assess the impact of health staff on health promotion activities in Japanese worksites. We surveyed all worksites with 50 or more employees in Kagawa Prefecture, western Japan through self-administered questionnaires. We constructed a general linear model that contained three health professions, occupational physicians, health supervisors and occupational health nurses, which are common in the Japanese workplace as co-regressors, and fourteen health promotion activities as dependent variables. The impact of occupational physicians was small. The impact of health supervisors was considered high in workplace defined activities. The impact of occupational health nurses was considered high in person-to-person services and life-style related activities. Through assessing the impact, the strengths and weaknesses of each health professional were clarified.
\end{abstract}

(J Occup Health 2000; 42: 96-104)

Key words: Health promotion, Workplace, Health manpower, Occupational physician, Health supervisor, Occupational health nurse

The worksite has been identified as an appropriate target for health promotion activities ${ }^{1-5\rangle}$. Rationales come from the following characteristics: worksites are the place where a majority of the population spend a large amount of time, the age group of workers is appropriate for

Received Aug 9, 1999; Accepted Nov 22, 1999

Correspondence to: $T$. Hirao, Department of Hygiene \& Public health, Faculty of Medicine, Kagawa Medical University, Kagawa 761-0793, Japan interventions because most of the health promotion activities are for primary preventions of life-style related diseases. A wide variety of perceived benefits of health promotion activities were reported by several authors, especially from North America: morale ${ }^{6)}$, employees' health risk reduction ${ }^{7,8)}$, improvement in productivity ${ }^{9)}$ and in factors that influence productivity such as absenteeism ${ }^{10-12)}$, and a reduction in medical costs ${ }^{7}, 13,14$ ). Furthermore, firms have begun to offer multifactorial programs rather than single risk factor targeted programs ${ }^{3}$ 15). Some programs included employees' dependents, and collaborated with local societies ${ }^{3,16,17}$. To cover these broad areas, a comprehensive approach and the participation of various health staff were key issues.

In Japan, for the period of rapid economic growth since the early $1960 \mathrm{~s}$, the main concern for occupational safety and health was the prevention of occupational diseases and injuries that were caused by exposure to hazardous substances, accidents and so on. The prevention of lifestyle related diseases was recently added because the main causes of death in Japan shifted from communicable diseases to life-style related diseases such as cancer, heart disease and cerebrovascular disease ${ }^{18}$. The Ministry of Labor therefore launched the Total Health Promotion Plan (THP) in 1988, in which the structure, system and the health staff of worksite health organizations were recommended to promote workers' health. Many Japanese firms have provided health promotion activities at worksites ${ }^{19-22)}$, but in an era of healthcare reform, the utilization of limited resources, capital, materials, time and manpower is a basic concern in various sectors. Especially at worksites, the prolonged recession has made firms' budgets tighter, and firms are beginning to review the allocation of their limited resources. From the viewpoint of human resources, it is essential to review the roles of health professionals. 
The aim of this article is to assess the impact of health staff on health promotion activities in Japanese worksites, by constructing a multivariate model.

\section{Methods}

\section{Subjects}

The target population was all worksites in the private sector in Kagawa Prefecture, western Japan, with 50 or more employees. We used the 1993 list of worksites provided by the Kagawa Occupational Health Promotion Center. The survey was performed from March 9 through March 20, 1998. We mailed the self-administered questionnaires to all 850 worksites with 50 or more employees on the list. Health staff in charge were requested to answer from the standpoint of the worksite. In the questionnaire we asked demographic characteristics of employees: type of industry, health promotion activities performed during the last twelve months, assignment or employment of occupational health staff and respondent's position at the worksite. To each questionnaire was attached a sheet on which we explained the scientific purpose of the study and the publication of the results for informed consent.

5 worksites did not receive the questionnaire because they were closing or moving. Of the 436 worksites that returned the questionnaires, $424(50.2 \%)$ were completed. Because we used the 1993 list, 55 of the worksites had less than 50 employees at the time of the survey. 369 worksites with 50 or more employees were eligible for the analysis. Of the 369 worksites, $162(43.9 \%)$ had 50 99 employees, $129(35.0 \%)$ had 100-199, $31(8.4 \%)$ had $200-299,18(4.9 \%)$ had $300-399,5(1.4 \%)$ had $400-$ 499 and $24(6.5 \%)$ had 500 or more. In industry type, $184(49.9 \%)$ were manufacturing, $35(9.5 \%)$ were wholesale/retail/real estate/insurance, $37(10.0 \%)$ were utilities/transportation/communication, 54 (14.6\%) were service, and $59(16.0 \%)$ were others. Because we considered the size of the worksite and industry type as potential confounders, all worksites were stratified by size and industry type. Worksites with 200 or more employees were combined into a single category to balance the distribution.

\section{Definitions of Health professionals}

We asked about the assignment or employment of occupational physicians, health supervisors, occupational health nurses (including licensed public health nurses), dentists, physical exercise instructors, counselors, nutritional instructors and occupational health instructors. When each professional was assigned or employed, the pattern of service was asked about in a dichotomous question, full-time or part-time. In this study we focused on three health professions that are relatively common in Japanese worksites: occupational physicians, health supervisors and occupational health nurses as job variables.

Occupational physicians are stipulated in the Industrial Safety and Health $\mathrm{Law}^{23)}$, and they are required at all worksites with 50 or more employees. They have to be physicians, and their role in workplaces is to prevent employees suffering from health disturbances, to promote employees' health and to advise employers as occupational health specialists. Because worksites with less than 1,000 employees generally do not have to assign occupational physicians as full-time staff, most of them practice at hospitals or clinics and concurrently serve in the worksite as part-time staff. The 1996 amendment to the Industrial Safety and Health Law requires all occupational physicians to be qualified through appropriate training courses after October 1998. At the time of this survey, we considered physicians assigned to worksites as occupational physicians.

Health supervisors are unique staff members in Japanese workplaces. They must be licensed and assigned as full-time employees, but most of them do not have a medical education. Their main role is to maintain a sanitary workplace and to promote workers' health. They are also required in all worksites with 50 or more employees.

Occupational health nurses are not stipulated in Japan, although a number of nurses have contributed in worksite settings. We considered the nurses who engaged in occupational health activities as occupational health nurses.

Other occupational health staff, such as physical exercise instructors, counselors, nutritional instructors and occupational health instructors were recommended to be employed in the THP. They are certified through short training programs and their fields of activities are specified. Only a few worksites employed these health professionals; 8 (2.2\%) worksites employed dentists, 15 $(4.1 \%)$ employed physical exercise instructors, $20(5.4 \%)$ employed counselors, $11(3.0 \%)$ employed nutritional instructors and $13(3.5 \%)$ employed occupational health instructors.

Job variables were categorized by their assignment or employment. The status was asked about in a dichotomous question, full-time or part-time. Because these terms were not defined clearly in the questionnaire, some respondents may have been confused. We only used assignment or employment in the analysis to remove the uncertainty. Occupational physicians and Health supervisors were categorized as "assigned" or "not assigned". Occupational health nurses were categorized as "employed" or "not employed".

\section{Definition of Worksite Health Promotion Activity}

Identifying worksite health promotion activities was not easy because there was no universal definition. According to the Ottawa Charter, health promotion is the 
process of enabling people to increase control over, and to improve their health ${ }^{24}$. Fielding et al. selected nine types of worksite health promotion activities in their national survey ${ }^{11}$. The 1992 National Survey of Worksite Health Promotion Activities by the U.S. Department of Health and Human Services selected eighteen subjects classified under four main areas: policies, screenings, information or activities, and facilities/services ${ }^{4}$. Most of the activities they selected were ones on primary prevention in life-style related diseases or injury. In this study we defined worksite health promotion activities as those designed to screen, promote health, or reduce highrisk behavior. We considered four areas and selected fourteen activities that reflect the Japanese work environment.

1. Activities related to health checkups (two activities).

- planning and implementing health checkups

- aftercare for health checkups

2. Activities confined to the workplace (three activities).

- worksite inspection

- improvement in work environment

- improvement in work method

3. Person-to-person services (two activities).

- health consultation

- counseling

4. Activities related to life-style (seven activities).

- stress management

- exercise and physical fitness

- nutritional education

- smoking control

- reducing alcohol consumption

- how to spend spare time

- safe driving

In Japan health checkups for employees are stipulated in the Industrial Safety and Health $\mathrm{Law}^{231}$, and include annual checkups, checkups at employment, and screening for employees in harmful environments such as dust and chemicals. In this study we focused on annual checkups. Activities confined to the workplace were to maintain a sanitary workplace and to prevent occupational diseases and on-the-job accidents. These are stipulated as roles of occupational physicians and health supervisors. Personto-person services are those provided individually. Activities related to life-style are those designed to reduce high-risk behavior as well as activities on exercise, nutrition and rest that are focused on the THP. Smoking control includes both guidance on smoking cessation and the environmental approach including the separation of smoking areas. If an activity was performed at least once during the last twelve months, we considered it in our study.

\section{Statistical Analysis}

The student's t test or analysis of variance (ANOVA) was used to compare frequencies of worksite health promotion activities by size, industry type and the assignment or employment status of each health professional. To evaluate the impact of each professional, a general linear model was constructed. The model contained the assignment status of occupational physicians and health supervisors, and the employment status of occupational health nurses as co-regressors to evaluate the impact of each professional. Size and industry type were also included to adjust their effects. Least square means (LSMs) were computed for each category.

\section{MODEL: Activity $=\mathrm{OP}+\mathrm{HS}+\mathrm{OHN}+$ Size + Industry Type \\ OP: Occupational Physician, HS: Health Supervisor, OHN: Occupational Health Nurse}

Because LSMs are predicted values, they may not reflect typical real-world values in the responses. We used LSMs for the purpose of comparing. Interaction effects were not assessed because the main purpose was to control the effect of confounders, and lack of fit test ${ }^{25}$ ) were not significant. $P$ values less than 0.05 were considered statistically significant. All statistical tests were run with a JMP ${ }^{26)}$ software package of the SAS Institute.

\section{Results}

Assignment or Employment of Health Professionals

Table 1 shows the frequencies of assignments or employment of health professionals by strata. The results are displayed in the observed number of worksites and percent (\%). $334(90.5 \%)$ worksites assigned occupational physicians, in which $305(82.7 \%)$ were parttime staff and only $29(7.9 \%)$ were full-time staff. 311 $(84.3 \%)$ worksites assigned health supervisors, and 84 $(22.8 \%)$ employed occupational health nurses. In the employment status of occupational health nurses, 62 $(16.8 \%)$ were full-time and $22(6.0 \%)$ were part-time. As the size of the worksites increased, more worksites assigned or employed health professionals and the prevalence of full-time staff increased. Although all worksites with 50 or more employees were required to assign occupational physicians and health supervisors, $35(9.5 \%)$ and $58(15.7 \%)$ answered "not assigned" respectively. 84 ( $22.8 \%$ ) employed occupational health nurses in spite of not being required. The frequency was lower than those of occupational physicians and health supervisors.

\section{Frequency of Worksite Health Promotion Activities by Size and Industry Type}

Table 2 shows the frequencies of worksite health promotion activities by size and industry type. The results are displayed as percentages $(\%)$ with standard error (SE). 
Table 1. Frequency of health professional assignment or employment at worksites

\begin{tabular}{|c|c|c|c|c|c|c|c|c|c|c|c|c|c|}
\hline & & \multicolumn{2}{|c|}{$\begin{array}{l}\text { Total number } \\
\text { of worksites }\end{array}$} & \multicolumn{4}{|c|}{ Occupational physician } & \multicolumn{2}{|c|}{ Health supervisor } & \multicolumn{4}{|c|}{ Occupational health nurse } \\
\hline & & \multirow{2}{*}{ Total } & \multirow{2}{*}{$\%$} & \multicolumn{3}{|c|}{ assigned } & \multirow{2}{*}{ not assigned } & \multirow{2}{*}{ assigned } & \multirow{2}{*}{ not assigned } & \multicolumn{3}{|c|}{ employed } & \multirow{2}{*}{ not employed } \\
\hline & & & & total & full-time & part-time & & & & total & full-time & part-time & \\
\hline \multirow[t]{3}{*}{ Worksite size } & $50-99$ & 162 & 43.9 & $139(85.8)$ & $7(4.3)$ & $132(81.5)$ & $23(14.2)$ & $128(79.0)$ & $34(21.0)$ & $24(14.8)$ & $16(9.9)$ & $8(4.9)$ & $138(85.2)$ \\
\hline & $100-199$ & 129 & 35.0 & $118(91.5)$ & $9(7.0)$ & $109(84.5)$ & $11(8.5)$ & $112(86.8)$ & $17(13.2)$ & $23(17.8)$ & $14(10.9)$ & $9(7.0)$ & $106(82.2)$ \\
\hline & 200 & 78 & 21.1 & $77(98.7)$ & $13(16.7)$ & $64(82.1)$ & $1(1.3)$ & $71(91.0)$ & $7(9.0)$ & $37(47.4)$ & $32(41.0)$ & $5(6.4)$ & $41(52.6)$ \\
\hline \multicolumn{14}{|l|}{ Industry type } \\
\hline \multicolumn{2}{|c|}{ Manufacturing } & 184 & 49,9 & $177(96.2)$ & $5(2.7)$ & $172(93.5)$ & $7(3.8)$ & $167(90.8)$ & $17(9.2)$ & $31(16.9)$ & $21(11.4)$ & $10(5.4)$ & $153(83.1)$ \\
\hline \multicolumn{2}{|c|}{ Wholesale/Retail/Real Estate/Insurance } & 35 & 9.5 & $28(80.0)$ & $0(0.0)$ & $28(80.0)$ & $7(20.0)$ & $24(68.6)$ & $11(31.4)$ & $6(17.1)$ & $5(14.3)$ & $1(2.9)$ & $29(82.9)$ \\
\hline \multicolumn{2}{|c|}{ Ubilities/Transportation/Communication } & 37 & 10.0 & $32(86.5)$ & $4(10.8)$ & $28(75.7)$ & $5(13.5)$ & $32(86.5)$ & $5(13.5)$ & $13(35.1)$ & $11(29.7)$ & $2(5.4)$ & $24(64.9)$ \\
\hline \multicolumn{2}{|c|}{ Service } & 54 & 14.6 & $48(88.9)$ & $17(31.5)$ & $31(57.4)$ & $6(11.1)$ & $38(70.4)$ & $16(29.6)$ & $20(37.0)$ & $17(31.5)$ & $3(5.6)$ & $34(63.0)$ \\
\hline \multicolumn{2}{|l|}{ Others } & 59 & 16.0 & $49(83.1)$ & $3(5.1)$ & $46(78.0)$ & $10(16.9)$ & $50(84.8)$ & $9(15.2)$ & $14(23.7)$ & $8(13.6)$ & $6(10.2)$ & $45(76.3)$ \\
\hline \multicolumn{2}{|l|}{ All worksites } & 369 & & $334(90.5)$ & $29(7.9)$ & $305(82.7)$ & $35(9.5)$ & $311(84.3)$ & $58(15.7)$ & $84(22.8)$ & $62(16.8)$ & $22(6.0)$ & $285(77.2)$ \\
\hline
\end{tabular}

Prevalence in observed number of worksites and percentage (\%).

Table 2. Frequency of occupational health activities by size and industry type

\begin{tabular}{|c|c|c|c|c|c|c|c|c|c|}
\hline & \multirow{2}{*}{\multicolumn{3}{|c|}{$\begin{array}{c}\text { Worksite size } \\
\text { (number of employees) }\end{array}$}} & \multirow[b]{3}{*}{ Manufacturing } & \multicolumn{4}{|c|}{ Industry type } & \multirow{3}{*}{$\begin{array}{c}\text { All } \\
\text { worksites }\end{array}$} \\
\hline & & & & & Wholesale & Utilities & & & \\
\hline & $50-99$ & $100-199$ & $200-$ & & $\begin{array}{c}\text { Retail/Real } \\
\text { Estate/Insurance }\end{array}$ & $\begin{array}{l}\text { Transportation } \\
\text { Communication }\end{array}$ & Service & Others & \\
\hline \multicolumn{10}{|l|}{ 1. Activities related to health checkups } \\
\hline Planning and implementing health checkups & $91.4(2.2)$ & $94.6(2.0)$ & $96.2(2.2)$ & $93.5(1.8)$ & $94.3(4.0)$ & $86.5(5.7)$ & $98.1(1.9)$ & $93.2(3.3)$ & $93.5(1.3)$ \\
\hline Aftercare for health checkups & $66.7(3.7)$ & $74.4(3.9)$ & $74.4(5.0)$ & $69(3.4)$ & $54.3(8.5)$ & $73.0(7.4)$ & $83.3(5.1)$ & $74.6(5.7)^{*}$ & $71.0(2.4)$ \\
\hline \multicolumn{10}{|l|}{ 2. Activities confined to the workplace } \\
\hline Worksite inspection & $47.5(3.9)$ & $47.3(4.4)$ & $65.4(5.4)^{*}$ & $66.3(3.5)$ & $25.7(7.5)$ & $64.9(8.0)$ & $20.4(5.5)$ & $39.0(6.4)^{* *}$ & $51.2(2.6)$ \\
\hline Improvement in work environment & $44.4(3.9)$ & $41.1(4.3)$ & $51.3(5.7)$ & $63.6(3.6)$ & $22.9(7.2)$ & $29.7(7.6)$ & $27.8(6.2)$ & $23.7(5.6)^{* *}$ & $44.7(2.6)$ \\
\hline Improvement in work method & $43.8(3.9)$ & $36.4(4.3)$ & $41.0(5.6)$ & $61.4(3.3)$ & $17.1(7.6)$ & $27.0(7.3)$ & $14.8(6.0)$ & $22.0(5.8)^{* *}$ & $40.7(2.6)$ \\
\hline \multicolumn{10}{|l|}{ 3. Person-to-person services } \\
\hline Health consultation & $25.3(3.4)$ & $39.5(4.3)$ & $55.1(5.7)^{* *}$ & $38.6(3.6)$ & $34.2(8.1)$ & $48.6(8.3)$ & $31.5(6.4)$ & $28.8(5.9)$ & $36.6(2.5)$ \\
\hline Counseling & $3.7(1.5)$ & $3.1(1.5)$ & $19.2(4.5)^{* *}$ & $6.0(1.8)$ & $2.9(2.9)$ & $13.5(5.7)$ & $7.4(3.6)$ & $6.8(3.3)$ & $6.8(1.3)$ \\
\hline \multicolumn{10}{|l|}{ 4. Activities related to life-style } \\
\hline Stress management & $4.3(1.6)$ & $4.7(1.9)$ & $16.7(4.2)^{* *}$ & $6.5(1.8)$ & $8.6(4.8)$ & $8.1(4.5)$ & $5.5(3.1)$ & $8.5(3.7)$ & $7.1(1.3)$ \\
\hline Exercise and physical fitness & $6.8(2.0)$ & $4.7(1.9)$ & $14.1(4.0)^{*}$ & $9.2(2.1)$ & $2.9(2.9)$ & $16.2(6.1)$ & $3.7(2.6)$ & $3.4(2.4)$ & $7.6(1.4)$ \\
\hline Nutritional education & $2.5(1.2)$ & $4.7(1.9)$ & $12.8(3.8)^{* *}$ & $2.1(1.1)$ & $2.9(1.1)$ & $10.8(5.2)$ & $9.3(4.0)$ & $10.2(4.0)^{*}$ & $5.4(1.2)$ \\
\hline Smoking control & $17.9(3.0)$ & $21.7(3.6)$ & $43.6(5.7)^{* *}$ & $22.8(3.1)$ & $20.0(6.9)$ & $27.0(7.4)$ & $25.9(6.0)$ & $30.5(6.0)$ & $24.7(2.3)$ \\
\hline Reducing alcohol consumption & $4.9(1.7)$ & $6.2(2.1)$ & $12.8(3.8)$ & $8.2(2.0)$ & $5.7(4.0)$ & $10.8(5.2)$ & $0.0(0.0)$ & $8.5(3.7)$ & $7.1(1.3)$ \\
\hline How to spend spare time & $3.1(1.4)$ & $3.1(1.5)$ & $6.4(2.8)$ & $3.3(1.3)$ & $5.7(4.0)$ & $5.4(3.8)$ & $0.0(0.0)$ & $6.8(3.3)$ & $3.8(1.0)$ \\
\hline Safe driving & $47.5(3.9)$ & $48.8(4.4)$ & $50.0(5.7)$ & $51.1(3.7)$ & $42.9(8.5)$ & $70.3(7.6)$ & $31.5(6.4)$ & $45.8(6.5)^{* *}$ & $48.5(2.6)$ \\
\hline Number of worksites & 162 & 129 & 78 & 184 & 35 & 37 & 54 & 59 & 369 \\
\hline
\end{tabular}

Prevalence as a $\%$ and standard error (SE). Note: ${ }^{*} p<0.05 ;{ }^{* *} p<0.01$. ANOVA was performed.

In activities related to health checkups, the overall frequencies of planning and implementing, and aftercare of health checkups were $93.5 \%$ and $71.0 \%$ respectively. There was no significant difference with the size of the industry. In activities confined to the workplace, the overall frequency of worksite inspection was $51.2 \%$, and increased with size. $66.3 \%$ of manufacturing and $64.9 \%$ of utilities/ transportation/ communication industries performed worksite inspections, but only $20.4 \%$ of service industries did. Improvements in the work environment and improvements in work methods were performed in $44.7 \%$ and $40.7 \%$ of these worksites, respectively. There were differences between industry types, but not according to size. Manufacturing performed improvements in the work environment and work method were $63.6 \%$ and $61.4 \%$ respectively. In person-to-person services, $36.6 \%$ of the worksites offered health consultation services. These frequencies increased with the size of the worksite. Although counseling services were offered in only $6.8 \%$ of the worksites, the frequency in worksites with 200 or more employees was $19.2 \%$. In activities related to lifestyle, the most frequent response was safe driving by $48.5 \%$, followed by smoking control by $24.7 \%$. The frequencies of safe driving differed by industry type; the highest was utilities/transportation/communication at $70.3 \%$, and the lowest was in services at $31.5 \%$. Frequencies of smoking control increased by size; $43.6 \%$ offered it in worksites with 200 or more employees. Although the overall prevalence of the other five activities was less than $10 \%$, the worksites with 200 or more employees offered more activities in stress management, physical exercise and fitness, and nutritional education. 
Table 3. Frequency of occupational health activities by assignment or employment status

\begin{tabular}{|c|c|c|c|c|c|c|c|}
\hline & \multicolumn{2}{|c|}{ Occupational physician } & \multicolumn{2}{|c|}{ Health supervisor } & \multicolumn{2}{|c|}{ Occupational health nurse } & \multirow[b]{2}{*}{ All worksites } \\
\hline & assigned & not assigned & assigned & not assigned & employed & not employed & \\
\hline \multicolumn{8}{|l|}{ 1. Activities related to health checkups } \\
\hline Planning and implementing health checkups & $94.3(1.3)$ & $85.7(6.0)^{*}$ & $93.6(1.4)$ & $93.1(3.4)$ & $94.0(2.6)$ & $93.3(1.5)$ & $93.9(1.2)$ \\
\hline Aftercare for health checkups & $72.5(2.4)$ & $57.1(8.5)$ & $74.9(2.5)$ & $50.0(6.6)^{* *}$ & $90.5(3.2)$ & $65.3(2.8)^{* *}$ & $70.8(2.2)$ \\
\hline \multicolumn{8}{|l|}{ 2. Activities confined to the workplace } \\
\hline Worksite inspection & $53.6(2.7)$ & $28.6(7.7)^{* *}$ & $57.2(2.7)$ & $19.0(6.3)^{* *}$ & $63.1(5.3)$ & $47.7(3.0)^{*}$ & $48.4(2.4)$ \\
\hline Improvement in work environment & $47.9(2.7)$ & $14.3(6.0)^{* *}$ & $49.5(2.8)$ & $19.0(6.4)^{* *}$ & $48.8(5.5)$ & $43.5(2.9)$ & $42.7(2.4)$ \\
\hline Improvement in work method & $42.8(2.7)$ & $20.0(6.9)^{* *}$ & $44.7(2.7)$ & $19.0(6.3)^{* *}$ & $39.3(5.4)$ & $41.1(2.9)$ & $39.9(2.4)$ \\
\hline \multicolumn{8}{|l|}{ 3. Person-to-person services } \\
\hline Health consultation & $38.0(2.7)$ & $22.9(7.2)$ & $38.9(2.8)$ & $24.1(5.7)^{*}$ & $71.4(5.0)$ & $26.3(2.6)^{* *}$ & $35.6(2.3)$ \\
\hline Counseling & $7.2(1.4)$ & $2.9(2.9)$ & $7.0(1.5)$ & $5.2(2.9)$ & $19.0(4.3)$ & $3.2(1.0)^{* * *}$ & $6.4(1.2)$ \\
\hline \multicolumn{8}{|l|}{ 4. Activities related to life-style } \\
\hline Stress management & $7.5(1.4)$ & $2.9(2.9)$ & $8.0(1.5)$ & $1.7(1.7)$ & $25.0(4.8)$ & $1.8(0.7)^{* *}$ & $6.4(1.2)$ \\
\hline Exercise and physical fitness & $8.1(1.5)$ & $2.9(2.9)$ & $8.4(1.6)$ & $3.4(2.4)$ & $23.8(4.7)$ & $2.8(1.0)^{* *}$ & $7.3(1.3)$ \\
\hline Nutritional education & $6.0(1.3)$ & $0.0(0.0)$ & $5.1(1.3)$ & $6.9(3.4)$ & $21.4(4.5)$ & $0.7(0.4)^{* *}$ & $4.7(1.0)$ \\
\hline Smoking control & $25.7(2.4)$ & $14.3(6.0)$ & $27.0(2.5)$ & $12.1(4.3)^{*}$ & $51.2(5.5)$ & $16.8(2.2)^{* *}$ & $23.1(2.1)$ \\
\hline Reducing alcohol consumption & $7.2(1.4)$ & $5.7(4.0)$ & $8.4(1.6)$ & $0.0(0.0)^{*}$ & $15.5(4.0)$ & $4.6(1.2)^{* *}$ & $6.8(1.2)$ \\
\hline How to spend spare time & $4.2(1.1)$ & $0.0(0.0)$ & $4.2(1.1)$ & $1.7(1.7)$ & $7.1(2.8)$ & $2.8(1.0)$ & $3.5(0.9)$ \\
\hline Safe driving & $49.7(2.7)$ & $37.1(8.3)$ & $52.7(2.8)$ & $25.9(6.4)^{* *}$ & $53.6(5.5)$ & $47.0(3.0)$ & $46.2(2.4)$ \\
\hline Number of worksites & 334 & 35 & 311 & 58 & 84 & 285 & 369 \\
\hline
\end{tabular}

Prevalence as a $\%$ and standard error (SE). Note: ${ }^{*} \mathrm{p}<0.05 ;{ }^{* *} \mathrm{p}<0.01$. ANOVA or $\mathrm{t}$-test was performed.

Table 4. Frequency of occupational health activities by assignment or employment status after adjustment

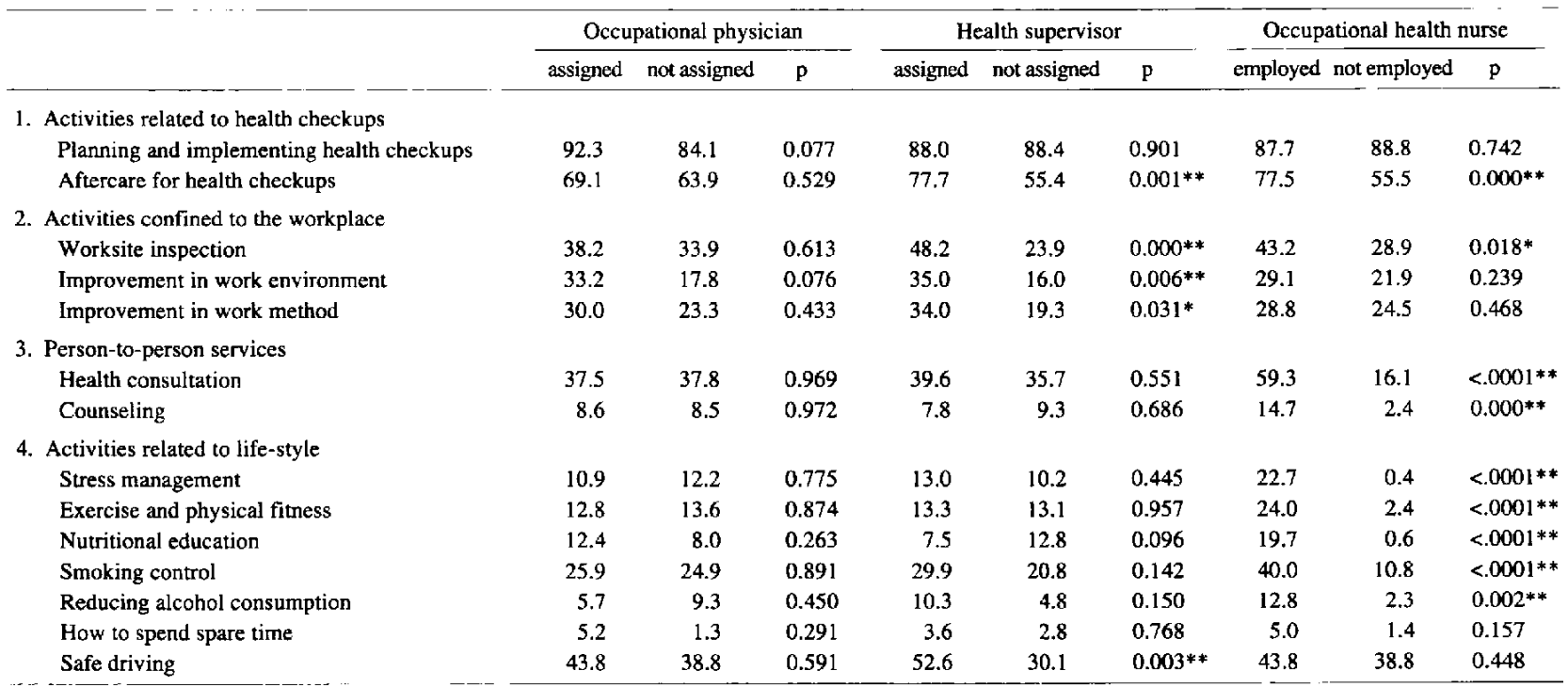

Prevalence in least square mean (\%). Note: ${ }^{*} \mathrm{p}<0.05 ;{ }^{* *} \mathrm{p}<0.01$. Linear Model was executed.

Frequency of Worksite Health Promotion Activities by Assignment or Employment of Professionals

Table 3 shows the frequencies of worksite health promotion activities by assignment or employment status. The results are displayed as percentages (\%) with standard error (SE). Table 4 shows the LSMs of the frequencies after adjustment.

\section{Occupational Physicians}

In health checkup related activities, the frequency of planning and implementing health checkups in "assigned" worksites was $94.3 \%$, more than in "not assigned". Aftercare for health checkups was $72.5 \%$. In activities confined to the workplace, the frequencies of worksite inspections, improvements in the work environment and improvements in work methods were $53.6 \%, 47.9 \%$ and $42.8 \%$, respectively. All of them were larger than those 
in "not assigned". In person-to-person services, the frequencies of health consultation and counseling in "assigned" were $38.0 \%$ and $7.2 \%$ respectively. In activities related to life-style, the frequencies were less than $10 \%$, except smoking control and safe driving. After adjusting for size, industry type and the assignment and employment of two other health professions, no statistically significant association was observed in any of the fourteen activities.

\section{Health Supervisors}

In health checkup related activities, the frequency of planning and implementing health checkups in "assigned" was 93.6\%. Aftercare for health checkups in "assigned" was $74.9 \%$, and larger than in "not assigned". In activities confined to the workplace, the frequencies of worksite inspections, improvements in work environment and improvements in work methods in "assigned" were $57.2 \%, 49.5 \%$ and $44.7 \%$, respectively. All of them were larger than those in "not assigned". In person-to-person services, frequency of health consultation in "assigned" was $38.9 \%$, and larger than that in "not assigned". The frequency of counseling in "assigned" was $7.0 \%$. In activities related to life-style, the frequencies were less than $10 \%$, except smoking control and safe driving. The frequencies of smoking control, alcohol and safe driving in "assigned" were larger than those in "not assigned". After adjusting for size, industry type and the assignment or employment of two other health professions, an association was observed in the aftercare for health checkups, safe driving and three worksite-defined activities.

\section{Occupational Health Nurses}

In health checkup related activities, the frequency of planning and implementing health checkups in "employed" was $94.0 \%$. Aftercare for health checkups in "employed" was $90.5 \%$, and larger than that in "not employed". In activities confined to the workplace, the frequencies of worksite inspections, improvements in work environment and improvement in work methods in "employed" were $63.1 \%, 48.8 \%$ and $39.3 \%$, respectively. Only worksite inspections were larger than in "not employed". In person-to-person services, the frequencies of health consultation and counseling in "employed" were $71.4 \%$ and $19.0 \%$ respectively. Both were larger than those in "not employed".

In activities related to life-style, the frequencies in worksite "employed" occupational health nurses were larger than in worksite "assigned" occupational physicians and health supervisors. The frequency of stress management was $25.0 \%$, exercise and physical fitness was $23.8 \%$, nutritional education was $21.4 \%$, smoking control was $51.2 \%$, reducing alcohol consumption was $15.5 \%$, how to spend spare time was $7.1 \%$, and safe driving was $53.6 \%$. In five activities other than how to spend spare time and safe driving, the association with employment status existed even after adjustment.

\section{Discussion}

The results suggested the characteristics of each health professional. From the frequencies before adjustment, we can estimate the magnitude of frequencies. Because the model contained three job variables as co-regressors, and showed the predicted values when other job variables were fixed, we can assess the impact of "assignment" or "employment" on the frequency of worksite health promotion activities.

When discussing the contribution of health staff to a certain community, it should be assessed from the viewpoint of health care management. Because the worksite can be considered an appropriate community in which to intervene, the following were discussed from this standpoint. Collings ${ }^{27}$ classified health care management into three conceptual levels. Level $I$ is the management of a specific illness and injury, or clinical medicine. Level II management deals with the health of whole individuals with a lifetime health strategy. Level III management concerns the employee population and the system. It applies the principles of epidemiology and administration.

In the Japanese system, Level I management, treatment of employees' illness and injury, is usually provided by medical staff in hospitals or clinics, not by occupational health staff. Management in Levels II and III is required for occupational health staff. Fourteen activities we surveyed, health checkup related activities, workplacedefined activities, person-to-person services, and life-style related activities were considered in Level II.

\section{Impact of Occupational Physicians}

In this study no statistically significant association was found between the assignment of occupational physicians and the fourteen worksite health promotion activities. Although the impact of occupational physicians on these activities and their roles in Level II management are considered insufficient, the significance of the occupational physician in planning and implementing health checkups $(\mathrm{p}=0.077)$ and improvement in work environment $(\mathrm{p}=0.076)$ cannot be denied.

As a reason for their low impact in Level II management, we consider the assignment status of occupational physicians. Under the present law, worksites with less than 1,000 employees generally do not have to assign occupational physicians as full-time staff. Because most worksites are smaller, most occupational physicians were part-time staff who had regular practices at hospitals or clinics. Inevitably the time they spent on worksite health promotion activities was short. Koda et al. reported the occupational health activities of part-time 
occupational physicians did not reach their requirements in their 1995-96 survey in Kochi Prefecture, western Japan $^{28)}$. Their findings partially supported ours. Because this situation will not change in the near future, the contribution of occupational physicians to worksite health promotion activities will be limited.

A role we did not survey was that occupational physicians are expected to advise or make recommendations to employers from the viewpoint of an occupational health professional. Furthermore, occupational physicians, especially part-time staff, are encouraged to support other health staff to develop skills and knowledge, and to assess the environmental status of the whole worksite. These activities are considered Level III. Occupational physicians therefore need to acquire skills and knowledge of occupational health, statistics, epidemiology and preventive medicine. The 1996 amendment to the Industrial Safety and Health Law required all occupational physicians to be qualified through appropriate training courses after October 1998. It is expected to promote occupational physicians as specialists.

\section{Impact of Health Supervisors}

The characteristics of health supervisors were the association with the activities confined to the workplace. The impact of these activities was considered high in this area. Health supervisors are encouraged to take advantage of their full-time status and to be well acquainted with specific worksite problems, and to arrange and coordinate worksite health promotion activities by working as a liaison among employers, employees and other health professionals.

On the other hand, full-time status may limit their activities. Because health supervisors are assigned from full-time employees, they may be sensitive to their employers or hesitate to express their opinions. Furthermore, because most health supervisors do not have a medical education, they may also be sensitive to other occupational health staff. To facilitate the activities, the legislative authorization and the assurance of job independence were recommended.

\section{Impact of Occupational Health Nurses}

The employment of occupational health nurses was associated with nine of fourteen activities. In person-toperson services and life-style related activities, the associations were closer than those of occupational physicians and health supervisors. The impact of occupational health nurses was considered high in these areas, especially in stress management, exercise and fitness, nutritional education, smoking control, and reducing alcohol consumption.

To explain the reason for the high impact in their activities, we assessed the characteristics of nursing itself. Occupational health nursing has been described as the application of nursing principles ${ }^{291}$. Because nursing has strengths in these activities, the results may not be surprising. Nowadays occupational health nurses are expected to engage in more and more activities at Levels II and III $^{30-32)}$. To meet these expanding needs, occupational health nurses should acquire more knowledge and skill to exercise their specialty ${ }^{33}$.

From the viewpoint of the worksite, occupational health nurses are efficient staff, especially in strengthening person-to-person services and life-style related activities. Companies should make use of occupational health nurses as utility players. To facilitate the employment of occupational health nurses, the legislation of their status at the worksite was recommended.

According to the 1996 census $^{34.35)}$, the distributions of the size and industry type of the privately owned worksites in Kagawa Prefecture were almost the same as the distributions throughout the whole country (Table 5), but the distribution pattern of the sample worksites was higher in 200 or more and lower in 50-99. Because the size of the manufacturing industries tends to be larger than wholesale/retail/real estate/insurance and service

Table 5. Distribution of worksite size and industry type

\begin{tabular}{|c|c|c|c|c|}
\hline & & This study & Kagawa & Japan \\
\hline \multirow[t]{3}{*}{ Worksite size } & $50-99$ & $43.9 \%$ & $65.9 \%$ & $62.8 \%$ \\
\hline & $100-199$ & $35.0 \%$ & $23.8 \%$ & $24.1 \%$ \\
\hline & $200-$ & $21.1 \%$ & $10.3 \%$ & $13.0 \%$ \\
\hline \multicolumn{5}{|l|}{ Industry type } \\
\hline \multicolumn{2}{|c|}{ Manufacturing } & $49.9 \%$ & $33.3 \%$ & $27.7 \%$ \\
\hline \multicolumn{2}{|c|}{ Wholesale/Retail/Real Estate/Insurance } & $9.5 \%$ & $23.6 \%$ & $26.9 \%$ \\
\hline \multicolumn{2}{|c|}{ Utilities/Transportation/Communication } & $10.0 \%$ & $10.1 \%$ & $11.1 \%$ \\
\hline \multicolumn{2}{|l|}{ Service } & $14.6 \%$ & $23.6 \%$ & $26.1 \%$ \\
\hline \multicolumn{2}{|l|}{ Others } & $16.0 \%$ & $9.4 \%$ & $8.3 \%$ \\
\hline
\end{tabular}

Source: 1996 Establishment and enterprise census of Japan ${ }^{34,35}$. 
industries, the distribution of the sample worksites may be higher in manufacturing and lower in wholesale/retail/ real estate/insurance and services.

In our study $85.8 \%$ and $79.0 \%$ of the worksites with 50-99 employees assigned occupational physicians and health supervisors, respectively (Table 1). According to the 1995 national survey, the assignment rates were $63.9 \%$ and $68.0 \%{ }^{36)}$. Although more worksites may have assigned occupational physicians and health supervisors during the interval between the two studies, the possibility of bias cannot be denied. This may underestimate the impacts because it is considered that the more active the worksites are the more likely they are to respond to the questionnaire.

\section{Limitations}

The results had several limitations in interpretation. First, a response rate of $50.2 \%$ restricts the generalizability. Generally a response rate of more than $80 \%$ is recommended to ensure validity. This is considered to be due to the limitation of the surveillance by mail. This may also underestimate the health professional impacts for the reason given above. Second, this study was cross-sectional and the subjects were not sampled theoretically. For better evaluation, longitudinal designs with random allocation are desirable, but this is usually difficult to implement because time and subjects are limited. We used the 1993 directory of worksites provided by the Kagawa Occupational Health Promotion Center, which specified 850 worksites with 50 or more employees. According to the $1996 \mathrm{census}^{34)}$, there were 1231 privately owned worksites with 50 or more employees in Kagawa Prefecture. Randomness of subjects was not guaranteed. Third, of the respondents, $37.4 \%$ were health supervisors, $9.1 \%$ were occupational health nurses and none were occupational physicians. Although all respondents were requested to answer from the standpoint of their worksites, respondents' biases cannot be denied. Fourth, only frequencies of worksite health promotion activities were measured. To evaluate the impact of health staff, the benefits to employers and employees should also be measured. Furthermore, we did not consider the greatness of the number of participants or the duration of each activity. Even activities that were performed once a year were counted. It needs further consideration of their quality by using an index such as frequency of worksite inspection and professional meeting. Fifth, when the worksites assigned or employed the health professionals, we asked their status in a dichotomous question, full-time or part-time. Because these terms were not defined clearly in the questionnaire, some respondents may have been confused. In the analysis we used only the assignment or employment of the health professionals as job variables to remove the uncertainty. Sixth, for statistical convenience, we stratified the worksite into three categories. In the Japanese system worksites with 200 or more employees are required to assign more than one health supervisor depending upon the number of employees. Because we combined the worksites with 200 or more employees into a single category, the effect of the size may not be fully assessed.

\section{Conclusion}

Through assessing the impact of occupational physicians, health supervisors and occupational health nurses, the strengths and weaknesses of each health professional were clarified. Health protessionals were encouraged to intensify their strengths and to overcome their weaknesses. To facilitate their activities, not only their efforts but also environmental factors such as legislative support and assurance of job independence were recommended.

This study was done in collaboration with the Kagawa Occupational Health Promotion Center.

\section{References}

1) Ficlding JE, Piserchia PV. Frequency of health promotion activities. Am J Public Health 1989; 79: 1620.

2) Lusk SL. Health promotion and disease prevention in the worksite. Annu Rev Nurs Res 1997; 15: 187-213.

3) Pelletier KR. Clinical and Cost Outcomes of Multifactorial, Cardiovascular Risk Management Interventions in Worksites: A Comprehensive Review and Analysis. J Occup Environ Med 1997; 39: $1154-$ 1169.

4) U.S. Department of Health and Human Services, Public Health Service. 1992 National Survey of Worksite Health Promotion Activities: Summary. Am J Health Promotion 1993; 7: 452-464.

5) Blair SN, Piserchia PV, Wilbur CS, Crowder JH. A public health intervention model for work-site health promotion. Impact on exercise and physical fitness in a health promotion plan after 24 months. JAMA 1986; 255: 921-926.

6) Allegrante JP, Michela JL. Impact of a school-based workplace health promotion program on morale of inner-city teachers. J Sch Health 1990; 60: 25-28.

7) Gibbs JO, Mulvaney D, Henes C, Reed RW. Work-site health promotion. Five-year trend in employee health care costs. J Occup Med 1985; 27: 826-830

8) Shipley RH, Orleans CT, Wilbur CS, Piserchia PV, McFadden DW. Effect of the Johnson \& Johnson Live for Life program on employee smoking. Prev Med 1988; 17: 25-34.

9) Manuso JS. The Equitable Life Assurance Society program. Prev Med 1983; 12: 658-662.

10) Bertera RL. The effects of workplace health promotion on absenteeism and employment costs in a large industrial population. Am J Public Health 1990; 80: 1101-1105. 
11) Jones RC, Bly JL, Richardson JE. A study of a work site health promotion program and absenteeism. J Occup Med 1990; 32: 95-99.

12) Conrad KM, Riedel JE, Gibbs JO. Effect of worksite health promotion programs on employee absenteeism. A comparative analysis. AAOHN J 1990; 38: 573-580.

13) Bly JL, Jones RC, Richardson JE. Impact of worksite health promotion on health care costs and utilization. Evaluation of Johnson \& Johnson's Live for Life program. JAMA 1986; 256: 3235-3240.

14) Bowne DW, Russell ML, Morgan JL, Optenberg SA, Clarke AE. Reduced disability and health care costs in an industrial fitness program. J Occup Med 1984; 26: 809-816.

15) Emmons KM, Marcus BH, Linnan L, Rossi JS, Abrams DB. Mechanisms in multiple risk factor interventions: smoking, physical activity, and dietary fat intake among manufacturing workers. Working Well Research Group. Prev Med 1994; 23: 481-489.

16) Vass M, Walsh-Allis GA. Employee dependents: the future focus of worksite health promotion programs and the potential role of the allied health professional. J Allied Health 1990; 19: 39-48.

17) Stokols D, Pelletier KR, Fielding JE. Integration of medical care and worksitc health promotion. JAMA 1995; 273 : 1136-1142.

18) Statistics and information department, Minister's secretariat, Ministry of health and welfare. Vital statistics of Japan 1996, Volume 1. Tokyo; Ministry of health and welfare, 1998

19) Irie M, Nagata S, Ikeda M, Miyata M. Effect of walking during all weekdays, holidays, and at work on mental and physical health in workers. Sangyo Eiseigaku Zasshi 1998; 40: 7-14 (in Japanese).

20) Mitsumune T, Matsuo K, Funaki K, et al. Usefulness of exercise electro-cardiography in a THP. Sangyo Eiseigaku Zasshi 1997; 39: 186-190 (in Japanese).

21) Yanagita M. Present practice of total health promotion plan THP in Yamagata Prefecture. Nippon Koshu Eisei Zasshi 1997; 44: 488-494 (in Japanese).

22) Furuki K, Honda S, Jahng D, Ikeda M, Okubo T. The effect of a health promotion program on body mass index. J Occup Health 1999; 41: 19-26.

23) Ministry of Labour. Industrial Safety and Health Law. In: Ministry of Labour ed. Labour Laws of Japan. Tokyo: The Institute of Labour Administration; 1995: 161-224.

24) World Health Organization. Ottawa charter for health promotion. Can J Public Health 1986; 77: 425-430.

25) Sall J, Lehman A. JMP Start Statistics, A Guide to Statistical and Data Analysis Using JMP and JMP In Software. Belmont: Duxbury Press, 1996: 263-296.

26) SAS Institute Inc. JMP User's Guide. Version 3.1. Cary: SAS Institute Inc., 1995.

27) Collings, GH. Managing the health of employee. J Occup Med 1982; 24: 15-17.

28) Koda S, Yasuda N, Toyota M, Ohara H. A questionnaire study on improving occupational safety and health services provided by part-time industrial physicians. Sangyo Eiseigaku Zasshi 1998; 40: 91-100 (in Japanese).

29) Cox AR, Ryan P. Comprehensive Guide for Establishing an Occupational Health Service. Atlanta; American Association of Occupational Health Nurses, 1987.

30) Lusk SL. Selling health promotion programs: recommendations for occupational health nurses. AAOHN J 1992; 40: 414-418.

31) Lusk SL, Kerr MJ. Conducting worksite research: methodological issues and suggested approaches. AAOHN J 1994; 42: 177-181.

32) Shibata K. Expertise in occupational health nursing (1I)-Report on the 17 th UOEH International Symposium. Sangyo Ika Daigaku Zasshi 1998; 20: 259-272 (in Japanese).

33) Sato N. Role perception and expectation of occupational health nursing from survey in North Carolina. J Occup Health 1997; 39: 197-204.

34) Statistics Bureau, Management and Coordination Agency. 1996 Establishment and enterprise census of Japan, Volume 1--2, Results of establishments for Japan, privately owned establishments. Tokyo; Management and Coordination Agency, 1998.

35) Statistics Bureau, Management and Coordination Agency. 1996 Establishment and enterprise census of Japan, Volume2, Results of establishments for Prefectures, 37 Kagawa-ken Part1. Tokyo; Management and Coordination Agency, 1998.

36) Roudoudaijinkanbou seisakutyousabu toukeityousadainika. Heisei 7 nen roudouanzentyousakekka no gaiyou. Rousai 1996; 47(11): 6-14. (Second Statistics Division, Policy Planning \& Research Department, Minister's Secretariat, Ministry of Labor. A summary of the 1995 surveillance on occupational safety and health. Rousai $1996 ; 47(11): 6-14)$ 